\title{
ARTIGO
}

do https://doi.org/10.22481/rpe.v16i43.6500

\section{GRUPOS DE PESQUISA QUE INVESTIGAM A FORMAÇÃO DE PROFESSORES NO NORDESTE: QUEM SÃO, O QUE PRODUZEM E COMO PRODUZEM}

\author{
RESEARCH GROUPS INVESTIGATING TEACHER TRAINING IN THE NORTHEAST: \\ WHO ARE THEY, WHAT THEY PRODUCE AND HOW THEY PRODUCE \\ GRUPOS DE INVESTIGACIÓN QUE INVESTIGAN LA FORMACIÓN DE \\ PROFESORES EN EL NORESTE: QUIÉNES SON, QUÉ PRODUCEN Y CÓMO \\ PRODUCEN
}

\author{
Isabel Maria Sabino de Farias \\ Universidade Estadual do Ceará - Brasil \\ Marília Duarte Guimarães \\ Universidade Federal do Ceará - Brasil \\ Ingrid Louback de Castro Moura \\ Universidade Federal do Ceará - Brasil
}

Resumo: O trabalho focaliza grupos de pesquisa vinculados a pós-graduação stricto sensu em Educação do Nordeste que investigam a formação de professores, considerando indagações sobre quem são, o que produzem e como produzem essas equipes. Um exame teórico qualitativo, que adota como fonte o Currículo Lattes e o Diretório dos Grupos de Pesquisa do CNPq, contemplando amostra de 87 equipes, distribuídas pelos noves Estados nordestinos e ligadas a 15 programas. Um terço dessas equipes registra que investiga o assunto. São grupos robustos, apresentam foco temático diversificado, lideranças jovens, altamente qualificada e com forte capacidade de captação de financiamento de suas pesquisas.

Palavras chave: Formação de Professores; Grupos de Pesquisa; Nordeste.

\begin{abstract}
This paper focuses on research groups linked to the stricto sensu post graduation in Education in the Northeast that investigates teachers training, considering questions about Who are they, what they produce and how they produce these teams. A qualitative theoretical examination, which uses the Lattes Curriculum and the CNPq Research Groups Directory as a source, covering a sample of 87 teams, distributed across the nine northeastern states and linked to 15 programs. One third of these teams report that they investigate the matter. They are robust groups, have a diversified thematic focus, young leaders, highly qualified and with a strong capacity to attract funding for their research.
\end{abstract}

Keywords: Teachers training. Research groups. Northeast. 
Resumen: El trabajo se centra en grupos de investigación vinculados a programas de posgrado stricto sensu en Educación en el noreste que investigan la formación docente, considerando preguntas sobre quiénes son, qué producen y cómo producen estos equipos. Un examen teórico cualitativo, que utiliza el Currículo Lattes y el Directorio de Grupos de Investigación del CNPq como fuente, y que abarca una muestra de 87 equipos, distribuidos en los nueve estados del noreste y vinculados a 15 programas. Un tercio de dichos equipos informa que investigan el asunto. Son grupos sólidos, tienen un enfoque temático diversificado, líderes jóvenes, altamente calificados y con una fuerte capacidad para atraer fondos para su investigación.

Palabras clave: Formación docente. Grupos de investigación. Noreste.

\section{Introdução}

As últimas décadas têm registrado crescimento exponencial no interesse acadêmico sobre a formação de professores (FP), sendo significativo o volume de publicações, eventos e grupos de pesquisas que focalizam sua atenção sobre o assunto. Neste trabalho a atenção recai sobre este último segmento, precisamente sobre grupos de pesquisa vinculados a programas de pós-graduação stricto sensu em Educação do Nordeste que investigam a formação de professores, tendo como marco temporal o ano de 2018.

A análise partiu de indagações, provocadas no âmbito do Fórum de Coordenadores de Programas de Pós-Graduação em Educação do Nordeste (ANPED/FORPRED - NE), sobre quem são, o que produzem e como produzem grupos de pesquisa vinculados a pós-graduação stricto sensu em Educação do Nordeste que investigam a formação de professores, seja como foco principal dos estudos do grupo (todas as linhas focalizam a FP), seja como interesse específico de uma ou mais de suas linhas de pesquisa.

Obviamente que esta não é uma tarefa trivial, ainda mais em face do notável movimento de expansão da pós-graduação stricto sensu no Brasil. A CAPES, órgão responsável pela avaliação nesse âmbito, ao analisar os últimos períodos de avaliação (desde 2004) identificou que o número de cursos de mestrado e doutorado no país, considerando as 48 áreas de conhecimento, praticamente triplicou em 16 anos: se em 2000 havia 1.439 programas disponíveis, até 09/2018 esse número saltou para 4.319 (PLATAFORMA SUCUPIRA $^{1}$, 2018). A Área de Educação, por sua vez, nessa mesma data, registrou 252 cursos de pós-graduação, sendo 130 de Mestrado Acadêmico, 76 de Doutorado e 46 de Mestrado Profissional. Tais cursos se organizam em 176 Programas, 76 deles com Mestrado e

${ }^{1}$ Conforme consulta realizada em 22 de setembro de 2018, no endereço: https://sucupira.capes.gov.br/sucupira/public/consultas/coleta/programa/quantitativos/quantitativoAreaAvaliacao .jsf;jsessionid=1QHV2L8ZCixbuKGZvLV0M7pj.sucupira-214. 
Doutorado Acadêmicos, 54 com Mestrado Acadêmico e 46 com Mestrado Profissional. Além disso, é expressiva na avaliação do último quadriênio a melhora do conceito dos programas na Área.

No Nordeste, ainda de acordo com dados disponíveis na Plataforma Sucupira, são 23 as IES que ofertam formação pós-graduada stricto sensu em Educação, totalizando 44 cursos, sendo 20 de Mestrado Acadêmico, 11 de Doutorado e 13 de Mestrado Profissional. Estes cursos compõem um conjunto de 33 programas, dos quais apenas 11 são completos (possuem mestrado e doutorado). Quanto ao conceito desses programas, a região só possui programas avaliados com os conceitos 3, 4 e 5. Até o quadriênio 2013-2016 contou apenas com um único programa com conceito 5, o que se altera ao final de 2017 quando alcança cinco programas nesta faixa (UFPE, UFRN, UFBA, UNEB e UECE). Em meados de 2018 esse cômputo se altera novamente ${ }^{2}$ com o resultado dos recursos impetrados pelas IES em relação aos resultados da avaliação da quadrienal 2013-2016, quando a UFPI e a UNIT têm seu recurso acolhido. Com esse resultado o Nordeste chega a 7 programas com conceito 5 .

Em face dessa abrangência, a delimitação do estudo demandou escolhas que permitissem cercar o objeto de análise e, ao mesmo tempo, produzir dados com potencial para fornecer um primeiro retrato sobre quem, o que e como se produz sobre a formação de professores no contexto dos grupos de pesquisa nordestinos vinculados a pós-graduação stricto sensu em Educação. Esta preocupação dá corpo ao próximo tópico desse texto.

\section{As escolhas do caminho - considerações metodológicas}

A ideia de balanço está na base da caracterização desse estudo, uma vez que sua proposição visa mapear e discutir a produção acadêmica de grupos de pesquisa do Nordeste que investigam a formação de professores e, sob esta ótica, seu desenho metodológico assume um "caráter inventariante e descritivo". Inventariante porque busca identificar os grupos de pesquisas da região que voltam seus estudos para a temática na área da Educação; Descritivo porque pretende detalhar as características dessas equipes e de suas produções.

No caso desta pesquisa, a referência a esse desenho metodológico não condensou a pretensão de exaustão da temática, a exemplo de um estado da arte (FERREIRA, 2002), mas sim de sistematização de um contorno inicial do tema objeto da análise, embora também

\footnotetext{
${ }^{2}$ Sobre isso consultar o resultado da $2^{\text {a }}$ Reunião Extraordinária do Conselho Superior (CS), de 01 de agosto de 2018 (http://www.capes.gov.br/conselho-superior/38-conteudo-estatico/sobre/8777-resultados-de-recursosinterpostos-ao-conselho-superior).
} 
motivado pelo intuito de "conhecer o já construído e produzido" (p. 259). Nesses termos, seu delineamento se aproxima mais de uma pesquisa de levantamento, tal como definido por Matos e Vieira (2001), ou seja, um estudo exploratório e descritivo, que lida com grande quantidade de dados e que, nesta investigação, está configurado como um levantamento por amostra. Um exame teórico qualitativo, que adotou como fonte documental básica para a produção dos dados a Plataforma Lattes (http://lattes.cnpq.br/), em particular o Currículo Lattes e o Diretório dos Grupos de Pesquisa no Brasil, tendo como marco temporal desse mapeamento, conforme já esclarecido, o ano de 2018.

A abrangência da oferta dos programas de pós-graduação stricto sensu em Educação do Nordeste configurou como um desafio inicial, o que exigiu a explicitação, de modo objetivo e claro, do foco da análise. O que se buscava? Grupos de pesquisa sobre formação de professores ou grupos de pesquisa que investigam a formação de professores? Optou-se por esta última formulação, entendendo que ela permitiria identificar tanto as equipes que abordam a formação de professores como foco principal de estudo de todas as suas linhas de pesquisa quanto aquelas em que o tema se apresenta como interesse específico do escopo de estudo de uma ou mais de suas linhas de pesquisa.

Este delineamento levou a outra decisão: a adoção de uma amostra com tamanho único e com distribuição equitativa entre os estratos de avaliação dos programas de pósgraduação stricto sensu em Educação existentes no Nordeste, ou seja, programas com conceito 3, 4 e 5. No momento desta definição (02/2018), a região contava apenas com cinco programas avaliados com conceito 5 (todos de IES públicas), o que motivou, na ocasião, a compor uma amostra de 45,45\% (=15) do universo dos 33 programas nordestinos então existentes.

Definida o tamanho da amostra da pesquisa - 15 programas, sendo 5 de cada conceito avaliativo - ainda era preciso constituí-la, ou seja, escolher os programas. Iniciou-se essa aproximação pelos programas com conceito 5, uma vez que este delineamento estava dado. A expectativa era, a partir desse movimento, ir definindo critérios que norteassem a aproximação aos grupos de pesquisa com conceitos 3 e 4 .

As páginas institucionais dos programas de pós-graduação stricto sensu em Educação disponíveis na web se apresentaram, nesse momento, como fonte basilar. Seu exame evidenciou, no caso dos cinco programas com conceito 5, a existência de 104 grupos de pesquisa distribuídos em cinco dos nove estados nordestinos, conforme detalhado no Quadro 1: 
Quadro 1: Grupos de Pesquisa vinculados a programas de pós-graduação stricto sensu em Educação com conceito 5 no Nordeste.

\begin{tabular}{|l|l|l|c|}
\hline \multicolumn{1}{|c|}{ Estado } & \multicolumn{1}{c|}{ IES } & \multicolumn{1}{c|}{ Programa } & No de GP $^{\mathbf{1}}$ \\
\hline Ceará & $\begin{array}{l}\text { Universidade Estadual do } \\
\text { Ceará - UECE }\end{array}$ & $\begin{array}{l}\text { Programa de Pós-Graduação em } \\
\text { Educação (PPGE) }\end{array}$ & 12 \\
\hline Bahia & $\begin{array}{l}\text { Universidade Federal da Bahia } \\
\text { - UFBA }\end{array}$ & $\begin{array}{l}\text { Programa de Pós-Graduação em } \\
\text { Educação (PPGE) }\end{array}$ & 18 \\
\hline Pernambuco & $\begin{array}{l}\text { Universidade Federal de } \\
\text { Pernambuco - UFPE }\end{array}$ & $\begin{array}{l}\text { Programa de Pós-Graduação em } \\
\text { Educação (PPGEdu) }\end{array}$ & 38 \\
\hline $\begin{array}{l}\text { Rio Grande do } \\
\text { Norte }\end{array}$ & $\begin{array}{l}\text { Universidade Federal do Rio } \\
\text { Grande do Norte - UFRN }\end{array}$ & $\begin{array}{l}\text { Programa de Pós-Graduação em } \\
\text { Educação (PPGEd) }\end{array}$ & 21 \\
\hline Piauî̉ & $\begin{array}{l}\text { Universidade Federal do Piauí } \\
\text { - UFPI }\end{array}$ & $\begin{array}{l}\text { Programa de Pós-Graduação em } \\
\text { Educação (PPGEd) }\end{array}$ & 15 \\
\hline
\end{tabular}

Fonte: Elaboração das autoras com base em dados do DGP/CNPq, consultado em 10/2018.

Para a produção e análise inicial de dados foram construídos quadros sinópticos acerca da configuração dos grupos de pesquisa a partir do nome, liderança, data de criação, situação do cadastro junto ao CNPq e linhas de pesquisa, entre outras informações, conforme se visualiza na Tabela 1.

\section{LEVANTAMENTO DOS GRUPOS DE PESQUISA QUE PESQUISAM A FORMAÇÃO DE PROFESSORES VINCULADOS A PROGRAMAS COM CONCEITO 5}

IES: Universidade Federal de Pernambuco (UFPE)

PPGE: Programa de Pós Graduação em Educação (PPGEduc)

Área de concentração do PPGE: Educação Contemporânea

Onde/ Como localizou as informações sobre o GP: https://www.ufpe.br/ppgedu e https://dgp.cnpq/dgp/

Total de GP vniculados ao Programa: 41

\begin{tabular}{|c|c|c|c|c|}
\hline Nome do GP & $\begin{array}{c}\text { Nome do líder do } \\
\text { GP } \\
\end{array}$ & Situação do GP & $\begin{array}{l}\text { Ano de criação } \\
\text { do GP }\end{array}$ & Linhas de pesquisa do GP \\
\hline \multirow[t]{2}{*}{$\begin{array}{l}\text { Representações } \\
\text { sociais e Educação }\end{array}$} & \multirow[t]{2}{*}{$\begin{array}{l}\text {-Leda Bezerra } \\
\text { Machado }\end{array}$} & \multirow{2}{*}{$\begin{array}{l}\text { Certificado Não } \\
\text { atualizado há mais } \\
\text { de } 12 \text { meses }\end{array}$} & \multirow[t]{2}{*}{2010} & $\begin{array}{l}\text { Representações sociais e } \\
\text { formações de professores }\end{array}$ \\
\hline & & & & $\begin{array}{l}\text { Representações Sociais e } \\
\text { Práticas Pedagógicas }\end{array}$ \\
\hline $\begin{array}{l}\text { Didática da Língua } \\
\text { Portuguesa }\end{array}$ & $\begin{array}{l}\text {-Artur Gomes de } \\
\text { Morais } \\
\text {-Telma Ferraz Leal }\end{array}$ & Certificado & 1996 & $\begin{array}{l}\text { Didática da Língua } \\
\text { Portuguesa }\end{array}$ \\
\hline \multirow[t]{2}{*}{$\begin{array}{l}\text { Teoria do Discurso e } \\
\text { Educação }\end{array}$} & \multirow{2}{*}{$\begin{array}{l}\text {-Gustavo Gilson } \\
\text { Sousa de Oliveira } \\
\text {-Anna Luíza Araújo } \\
\text { Ramos }\end{array}$} & \multirow[t]{2}{*}{ Excluído } & \multirow[t]{2}{*}{2014} & $\begin{array}{l}\text { Educação e Pluralismo } \\
\text { Religioso }\end{array}$ \\
\hline & & & & $\begin{array}{l}\text { Educação Subjetividade e } \\
\text { Diferença }\end{array}$ \\
\hline \multirow{4}{*}{$\begin{array}{l}\text { Discurso, } \\
\text { Subjetividade e } \\
\text { Educação }\end{array}$} & \multirow{4}{*}{$\begin{array}{l}\text {-Anna Luíza Araújo } \\
\text { Ramos } \\
\text {-Gustavo Gilson } \\
\text { Sousa de Oliveira }\end{array}$} & \multirow[t]{4}{*}{ Certificado } & \multirow[t]{4}{*}{2014} & $\begin{array}{l}\text { Educação e Pluralismo } \\
\text { Religioso }\end{array}$ \\
\hline & & & & $\begin{array}{l}\text { Educação Popular e } \\
\text { Movimentos sociais }\end{array}$ \\
\hline & & & & $\begin{array}{l}\text { Educação Gênero e } \\
\text { Sexualidade }\end{array}$ \\
\hline & & & & $\begin{array}{l}\text { Teoria do Discurso e } \\
\text { Educação }\end{array}$ \\
\hline
\end{tabular}

Tabela 1: Modelo do Quadro Sinóptico 1 usado para mapear informações dos GP (2018).

3 O PPGE da UFPI foi incluído na amostra para assegurar que todos os Estados nordestinos fossem contemplados na amostra, fato que ocorreu em 08/2018 quando o programa teve seu recuso aprovado pela CAPES, alcançando o conceito 5 na avaliação da quadrienal 2013-2016. 
No exame das informações detalhadas da tabela 1 foi observado se o nome do grupo ou de suas linhas de pesquisa contemplavam a formação de professores. Para isso consideramos a presença de termos como: formação, formação de professores, formação docente, formação e prática docente, formação inicial e formação continuada. Priorizamos, portanto, os grupos de pesquisa que faziam referência direta ao tema no seu nome ou no nome da linha de pesquisa, decisão que serviu de parâmetro de inclusão e também de exclusão de programas da amostra.

Desse primeiro movimento resultou a construção de novos quadros contendo o objetivo (ou ementa) da linha de pesquisa a partir do registrado no Diretório de Grupos de Pesquisa do CNPq, no ícone "ações" ("espelho da linha de pesquisa"), conforme permite visualizar a Tabela 2:

\section{LEVANTAMENTO DOS GRUPOS DE PESQUISA VINCULADOS A PROGRAMAS DE PÓS GRADUAÇÃO DO NORDESTE, CONCEITO 5}

IES: Universidade Estadual do Ceará (UECE)

PPGE: Programa de Pós-Graduação em Educação da UECE - PPGE

Área de concentração do PPGE: Formação de Professores

Onde/Como localizou as informações sobre o GP: http://www.uece.br/ppge/index.php/grupos-de-pesquisa e http://dgp.cnpq.br/dgp/

Total de GP vinculados ao Programa: 12

\begin{tabular}{|c|c|c|}
\hline Nome do GP & Linhas de Pesquisa do GP & ementa \\
\hline \multirow[t]{3}{*}{$\begin{array}{l}\text { Docência no } \\
\text { Ensino Superior } \\
\text { e na Educação } \\
\text { Básica }\end{array}$} & Didática, Trabalho e Ensinos & $\begin{array}{l}\text { Temos por objetivo refletir sobre a formação e a prática dos } \\
\text { professores nos diferentes graus de ensino na perspectiva da } \\
\text { Didática enquanto área da Pedagogia que se preocupa com os } \\
\text { fenômenos do ensinar e do aprender. }\end{array}$ \\
\hline & \multirow{2}{*}{$\begin{array}{l}\text { Formação Inicial e Contínua, } \\
\text { Desenvolvimento Profissional e } \\
\text { Identidade Docente }\end{array}$} & \\
\hline & & $\begin{array}{l}\text { Tratará dos fundamentos, funcionamento e financiamento e } \\
\text { difusão das diferentes modalidades na formação de professores } \\
\text { em continuum, das investigações sobre a vida e trabalho do } \\
\text { professor, sua atuação em sala de aula, construção de sua } \\
\text { identidade, suas trajetórias profissionais e desenvolvimento } \\
\text { docente }\end{array}$ \\
\hline \multirow{3}{*}{$\begin{array}{l}\text { Educação, } \\
\text { Cultura Escolar } \\
\text { e Sociedade } \\
\text { (EDUCAS) }\end{array}$} & $\begin{array}{l}\text { Política, Planejamento e Gestão } \\
\text { da Educação. }\end{array}$ & $\begin{array}{l}\text { Estuda a política e gestão educacional a partir da } \\
\text { reestruturação do estado e seus desdobramentos no projeto } \\
\text { educativo em curso. }\end{array}$ \\
\hline & $\begin{array}{l}\text { Formação Docente, } \\
\text { Desenvolvimento Profissional e } \\
\text { Aprendizagem }\end{array}$ & $\begin{array}{l}\text { Investiga as ideias, valores, crenças, saberes e práticas da } \\
\text { escola e dos sujeitos que a interagem, destacando o docente em } \\
\text { seu desenvolvimento profissional e pessoal, bem como os } \\
\text { processos de aprendizagem que se dão no cenário escolar sob a } \\
\text { perspectiva sócio histórico-cultural. }\end{array}$ \\
\hline & $\begin{array}{l}\text { História da Educação e Cultura } \\
\text { Escolar }\end{array}$ & $\begin{array}{l}\text { Investiga a história da Educação no Brasil e no Ceará em sua } \\
\text { relação com a cultura nacional, buscando compreender a } \\
\text { constituição dos modelos educacionais implantados no país, as } \\
\text { práticas das instituições escolares e seus sentidos histórico- } \\
\text { culturais na construção da profissão docente. }\end{array}$ \\
\hline
\end{tabular}

Tabela 2: Modelo do Quadro Sinóptico 2 usado para mapear informações dos GP (2018). 
A Tabela 2 mostra que foram incluídas os objetivos dos grupos de pesquisa. Com esse procedimento a intenção foi refinar a informação sobre o foco ou não dos estudos dessas equipes na formação de professores. Pressupôs-se que a descrição do objetivo evidenciaria a abordagem ou não do tema.

Esse conjunto de procedimentos caracterizou a definição dos 15 programas do Nordeste que comporiam a amostra e, a partir deles, a escolha dos grupos de pesquisa a eles vinculados que investigam a formação de professores, o que foi feito considerando quatros critérios: a) foco em IES públicas; b) uma composição que contemplasse cinco programas de cada conceito avaliativo existente na região (abrangendo todos os estratos avaliativos existentes); c) uma distribuição equitativa entre os Estados da região e os programas com conceitos 3, 4 e 5 (assegurando-se, de algum modo, certa abrangência regional); d) uma composição, a mais equilibrada possível, nos grupos dos conceitos 3 e 4 entre programas acadêmicos e profissionais (na ocasião não havia programas profissionais em Educação no Nordeste com conceito 5). Com esteio nesses critérios chegou-se a uma amostra com a configuração que pode ser visualizada no Quadro 2.

Quadro 2: Os 15 programas de pós-graduação stricto sensu em Educação do Nordeste que compõem a amostra por conceito, IES, Estado, modalidade, total de Grupos de Pesquisa a eles vinculados e daqueles que investigam a formação de professores

\begin{tabular}{|c|c|c|c|c|c|}
\hline $\begin{array}{l}\text { Con } \\
\text { ceito }\end{array}$ & $\begin{array}{c}\text { IES / } \\
\text { Programa }\end{array}$ & Estado & Tipo & $\begin{array}{c}\mathbf{N}^{0} \text { de GP } \\
\text { vinculado ao } \\
\text { programa }\end{array}$ & $\begin{array}{c}\mathrm{N}^{0} \text { de GP } \\
\text { investiga a FP }\end{array}$ \\
\hline \multirow{5}{*}{5} & UECE /PPGE & Ceará & Acad. & 12 & \multirow{5}{*}{35} \\
\hline & UFBA /PPGE & Bahia & Acad. & 18 & \\
\hline & UFPE / PPGEduc & Pernambuco & Acad. & 38 & \\
\hline & UFRN/PPGE & Rio G. do Norte & Acad. & 21 & \\
\hline & UFPI/PPGEd & Piauí & Acad. & 15 & \\
\hline \multirow{5}{*}{4} & UFMA/ PPGE & Maranhão & Acad. & 06 & \multirow{5}{*}{32} \\
\hline & UFS/PPGE & Sergipe & Acad. & 40 & \\
\hline & UFPB/ PPGE & Paraíba & Acad. & 45 & \\
\hline & IFRN/ PPGEP & Rio G. do Norte & Acad. & 05 & \\
\hline & UNEB/MPEJA & Bahia & Prof. & 09 & \\
\hline \multirow{5}{*}{3} & UFAL/PPGE & Alagoas & Acad. & 20 & \multirow{5}{*}{20} \\
\hline & URCA/MPE & Ceará & Prof. & 20 & \\
\hline & UFMA /PPGEEB & Maranhão & Prof. & 20 & \\
\hline & UFCG /PPGE & Paraíba & Acad. & 20 & \\
\hline & $\begin{array}{l}\text { UFRPE/FUNDAJ- } \\
\text { PPGECI }\end{array}$ & Pernambuco & Acad. & 20 & \\
\hline \multicolumn{4}{|c|}{ Tamanho da amostra } & 309 & 87 \\
\hline
\end{tabular}

Fonte: Elaboração das autoras com base em dados do DGP/CNPq, consultado em 10/2018.

O Quadro 2 mostra um total de 309 grupos de pesquisa vinculados aos 15 programas de pós-graduação stricto sensu no Nordeste que compõem a amostra deste estudo. Estes 
grupos estão localizados nos 9 estados do Nordeste, apresentando distribuição equitativa, uma vez que apenas Piauí, Sergipe e Alagoas constam com um programa em função de serem esses os únicos, nesses contextos, ofertados por instituição pública. Todos os programas com conceito 5 são acadêmicos. Dos três programas profissionais apenas um está situado na faixa do conceito 4, e os demais nos programas com conceito 3. Os critérios adotados possibilitaram configurar uma amostra com 15 programas, abrangendo os nove (9) estados do Nordeste e com $20 \%$ (=3) composta de programas profissionais.

Do universo de grupos de pesquisa que compõem a amostra de 15 programas de pósgraduação stricto sensu em Educação do Nordeste (309 GP), conforme anotado no Quadro 2, um conjunto de 87 equipes foram identificadas como grupos de pesquisa que investigam a formação de professores no Nordeste, considerando os procedimentos já detalhados. É sobre essas 87 equipes que concentramos as análises apresentadas neste trabalho.

As informações sobre cada aspecto/tema foram organizadas em quadros sinópticos e, posteriormente, integradas e discutidas tendo em vista o propósito orientador da pesquisa, explicitado na introdução deste texto. É importante destacar as dificuldades de realizar um levantamento a partir de bases digitais devido à reduzida visibilidade dos grupos de pesquisa nas páginas institucionais dos programas de pós-graduação; a desatualização de algum desses sítios; e, a debilidade das informações registradas no Diretório dos Grupos de Pesquisa do $\mathrm{CNPq}$ decorrente de seu preenchimento incompleto, de modo que alguns grupos não tinham, até o momento da coleta desses dados, anotado os objetivos de suas linhas de pesquisa ou, então, apenas colocaram palavras-chaves.

Enfim, esse foi o caminho adotado na aproximação às produções dos grupos de pesquisa do Nordeste vinculados a pós-graduação stricto sensu em Educação que declaram investigar a formação de professores, análise que reputamos como primordial a compreensão e projeção de novas perspectivas para os processos associativos na produção do conhecimento em geral, e em especial no campo da formação de professores.

\section{Processos Associativos, Produção do Conhecimento e Formação de Novos Pesquisadores - alguns apontamentos}

Uma pequena obra sobre pesquisa em Educação, escrita no início do século 21, ressalta o "caminhar em grupo" como via fértil para contribuir com o avanço do conhecimento nos diversos setores da vida social (CAVALCANTE; NUNES; FARIAS, 
2002). Com efeito, o potencial de processos associativos na produção do conhecimento nas mais diferentes áreas tem se revelado uma tendência da ciência contemporânea, movimento que agregou valor a constituição de equipes, de coletivos de estudo e trabalho nas instituições de ensino superior.

No Brasil, esse movimento encontra na expansão da pós-graduação stricto sensu um de seus elementos propulsores, manifestando-se no "aglutinamento de pesquisadores, experientes e iniciantes, que trabalham em colaboração" e constituídos institucionalmente como "grupos de pesquisa", designação popularizada sobretudo a partir das orientações do CNPq (FARIAS; RAMOS; PIMENTEL, 2018, p. 15).

Um grupo de pesquisa tem na liderança de um pesquisador experiente o seu elemento estruturante, uma vez que, em geral, parte dele e de seus interesses temáticos iniciais a concepção e o desenvolvimento desse ambiente investigativo e formador de novos pesquisadores. Este ambiente, por sua vez, é caracterizado "pelo compartilhamento ideológico, com condutas baseadas em normas, valores e crenças, e com relação interdependente entre os seus membros" (MOREIRA; VILAN FILHO; MUELER, 2015, p. 95).

Indicadores sobre o crescimento de grupos de pesquisa como estratégia de disseminação e fortalecimento da prática da investigação científica nas instituições formadoras e de pesquisa no país reforçam a importância desse processo associativo na produção do conhecimento. Dados do Censo de 2016 realizado pelo Conselho Nacional de Desenvolvimento Científico e Tecnológico (CNPq), o último com resultados publicizados no seu Diretório de Grupos de Pesquisa (DGP), mostra crescimento exponencial dos grupos de pesquisa. Há menos de três décadas, precisamente em 1993, o Brasil contava com apenas 99 instituições cadastradas, 21.541 pesquisadores e 4.402 grupos de pesquisa, dos quais 434 estavam no Nordeste. Em 2016, são 531 instituições, 199.566 pesquisadores e 37.640 grupos, sendo 7.713 situados no Nordeste. O alargamento e a robustez do processo associativo na forma de grupos de pesquisa evidenciam sua credibilidade junto aos pesquisadores brasileiros.

Este modo agregacionista, coletivo e compartilhado de concretizar a produção do conhecimento estabelece ruptura importante no trabalho individualizado de pesquisa até então prevalecente, forjando, nas últimas décadas, o que Plano Nacional de Pós-Graduação 20112020 (BRASIL, 2010) identifica como 'modo 2 de produção do conhecimento'. Ao analisarem esse movimento Farias, Ramos e Pimentel (2018, p. 15) asseveram que: 
[...] a emergência e expansão da associação de pesquisadores em torno de grupos de pesquisa, pode ser identificado como a 'nascente' do que o $\mathrm{CNPq}$ e demais agências de fomento da ciência, tecnologia e inovação no país reconhecem como modelo mais apropriado para enfrentar os desafios da pesquisa e produção de conhecimento na contemporaneidade.

Nascente porque é com a configuração desse ambiente de produção de conhecimento, e também de formação de novos pesquisadores, constituídos em diferentes centros de pesquisa, que novos parâmetros de aproximação e de compatibilização de culturas de investigação são forjadas. Com efeito, o aglutinamento de vários pesquisadores, experientes e iniciantes, em uma mesma equipe não se faz sem diálogo entre os integrantes, exige superação de relações dogmáticas em torno de paradigmas epistemológicos ou mesmo de um método, pressupondo a quebra do isolamento e a confrontação com outras compreensões e interpretações. Implica, sobretudo, "uma mudança epistemológica e teóricometodológica" no modo de conceber e produzir conhecimento e se colocar como pesquisador nesse processo (FARIAS et al., 2018, p. 30).

Os resultados da associação e colaboração de pesquisadores nas diversas áreas, em particular na Educação, tanto na produção de conhecimento mais abrangente e aprofundado quanto na formação de novos pesquisadores, são significativos, contribuindo para alterar o modo de produzir conhecimento e, decerto, de pensar e fazer a formação de pesquisadores. É o que buscamos evidenciar neste texto ao examinar como a formação de professores compõe o campo de investigação de grupos de pesquisa do Nordeste vinculados a pós-graduação stricto sensu em Educação, foco do próximo tópico deste escrito.

\section{Caracterização dos Grupos de Pesquisa que investigam a formação de professores no Nordeste: Quem produz}

As 87 equipes que investigam a formação de professores estão localizadas em 14 instituições públicas (UFAL, UFCG, UFRPE, UFMA, URCA, UFPB, UFS, UNEB, IFRN, UECE, UFBA, UFPE, UFRN e UFPI), distribuídos nos nove estados nordestinos e nos estratos avaliativos dos programas da região da seguinte maneira: 35 grupos de pesquisa são vinculados a programas com conceito 5, outros 32 grupos advêm de programas com conceito 4, enquanto 20 equipes são vinculadas a programas com conceito 3.

Apresenta-se, na sequência, caracterização desses 87 grupos de pesquisa, detalhada por estrato avaliativo dos programas (conceito 3, 4 e 5), especificando a situação de registro 
no Diretório de Grupos de Pesquisa do CNPq, o total de linhas de pesquisa que abordam a formação de professores e quantos grupos abordam este tema em todas as suas linhas.

Quadro 3: Caracterização geral dos 87 Grupos de Pesquisa que investigam a Formação de Professores em 15 PPGE do Nordeste.

\begin{tabular}{|c|c|}
\hline $\begin{array}{c}\text { Conceito/ } \\
\text { PPGE }\end{array}$ & Caracterização \\
\hline 3 & $\begin{array}{l}\text { Dos } 74 \text { grupos de pesquisa apenas } 68 \text { constam no Diretório de Grupos de Pesquisa do CNPq. } \\
\text { Desses } 68 \text { grupos de pesquisa um total de } 20 \text { aborda a formação de professores (FP), seja no } \\
\text { nome ou na linha de pesquisa. } \\
\text { Dos } 20 \text { grupos de pesquisa que abordam a formação de professores, que somam } 96 \text { linhas de } \\
\text { pesquisa, em apenas } 34 \text { delas a formação de professores é abordada explicitamente } \\
\text { (nominalmente). } \\
\text { Entre os } 20 \text { grupos de pesquisa que abordam a formação de professores apenas em } 3 \text { o tema é } \\
\text { abordado explicitamente em todas as suas linhas (ambos possuem apenas uma linha). }\end{array}$ \\
\hline 4 & $\begin{array}{l}\text { Dos } 105 \text { grupos de pesquisa um total de } 103 \text { constam no Diretório de Grupos de Pesquisa do } \\
\text { CNPq. } \\
\text { Desses } 103 \text { grupos de pesquisa um total de } 32 \text { aborda a formação de professores, seja no nome } \\
\text { ou na linha de pesquisa. } \\
\text { Dos } 32 \text { grupos de pesquisa que abordam a formação de professores, que somam } 134 \text { linhas de } \\
\text { pesquisa, em apenas } 35 \text { delas a formação de professores é abordada explicitamente } \\
\text { (nominalmente). } \\
\text { Entre os grupos de pesquisa que abordam a formação de professores apenas em } 2 \text { o tema é } \\
\text { abordado explicitamente em todas as suas linhas. }\end{array}$ \\
\hline 5 & $\begin{array}{l}\text { Dos } 104 \text { grupos de pesquisa apenas } 88 \text { constam no Diretório de Grupos de Pesquisa do CNPq. } \\
\text { Desses } 88 \text { grupos de pesquisa um total de } 35 \text { aborda a formação de professores, seja no nome } \\
\text { ou na linha de pesquisa. } \\
\text { Dos } 35 \text { grupos de pesquisa que abordam a formação de professores, que somam } 302 \text { linhas de } \\
\text { pesquisa, em apenas } 49 \text { delas a formação de professores é abordada explicitamente } \\
\text { (nominalmente). } \\
\text { Entre os } 35 \text { grupos de pesquisa que abordam a formação de professores apenas em } 11 \text { o tema } \\
\text { é abordado explicitamente em todas as suas linhas. }\end{array}$ \\
\hline
\end{tabular}

Fonte: Elaboração das autoras com base em dados do DGP/CNPq, consultado em 10/2018.

As 87 equipes desta amostra, denominadas como "grupos que investigam a formação de professores", receberam essa denominação, conforme já explicitado, porque abordam o tema explicitamente no seu nome ou no nome da linha de pesquisa. Todas se encontram cadastradas no Diretório de Grupos de Pesquisa do CNPq.

Outra informação que o Quadro 3 revela é que os 87 grupos de pesquisa juntos somam 525 linhas de pesquisa, das quais 118 (22,47\%) abordam a formação de professores. Um conjunto de 71 grupos de pesquisa, embora tenha mais de uma linha, apenas em uma o foco recai sobre a formação de professores, ou seja, prevalece a abordagem do tema em apenas uma linha de cada grupo pesquisa. É diminuto, por conseguinte, o total de grupos de pesquisa em que a formação de professores é explicitada em todas as linhas de pesquisa, precisamente apenas em $16(18,39 \%)$, conforme sintetiza o Quadro 4: 
Quadro 4: Grupos de Pesquisa que explicitam a formação de professores em todas as suas linhas nos 15 PPGE do Nordeste que compõem a amostra analisada, por estrato avaliativo, número de linhas, ano de criação e situação.

\begin{tabular}{|c|c|c|c|c|}
\hline $\begin{array}{l}\text { IES/ Conceito } \\
\text { do Programa }\end{array}$ & Nome do Grupo de Pesquisa & $\begin{array}{l}N^{0} \text { de linhas } \\
\text { de pesquisa }\end{array}$ & $\begin{array}{l}\text { Ano de } \\
\text { criação }\end{array}$ & Situação \\
\hline $\begin{array}{l}\text { UECE/PPGE } \\
\text { Conceito } 5\end{array}$ & $\begin{array}{l}\text { Docência no Ensino Superior e } \\
\text { na Educação Básica }\end{array}$ & 1 & 2003 & Certificado \\
\hline \multirow[t]{2}{*}{$\begin{array}{l}\text { UFBA } \\
\text { Conceito } 5\end{array}$} & $\begin{array}{l}\text { Currículo e Formação Docente } \\
\text { (FORMACCE) }\end{array}$ & 1 & 2009 & Certificado \\
\hline & $\begin{array}{l}\text { Formação em Exercício de } \\
\text { Professores (FEP) }\end{array}$ & 1 & 2006 & Certificado \\
\hline \multirow[t]{4}{*}{$\begin{array}{l}\text { UFPE } \\
\text { Conceito } 5\end{array}$} & $\begin{array}{l}\text { Grupo de Estudo em Formação } \\
\text { de Professores, Arte e Inclusão } \\
\text { (GEFAI) }\end{array}$ & 3 & 2011 & Em preenchimento \\
\hline & $\begin{array}{l}\text { Grupo de estudo em } \\
\text { alfabetização, prática docente e } \\
\text { formação de professor } \\
\text { (GEALPRAFOR) }\end{array}$ & 1 & 2017 & Certificado \\
\hline & $\begin{array}{l}\text { Formação de professores e } \\
\text { profissionalização docente }\end{array}$ & 2 & 1999 & Certificado \\
\hline & $\begin{array}{l}\text { Formação e atuação profissional } \\
\text { de professores de música }\end{array}$ & 2 & 2010 & Certificado \\
\hline \multirow[t]{4}{*}{$\begin{array}{l}\text { UFPI } \\
\text { Conceito } 5\end{array}$} & $\begin{array}{l}\text { Núcleo Interdisciplinar de } \\
\text { Pesquisa em Práticas } \\
\text { Curriculares e Formação de } \\
\text { Profissionais da Educação } \\
\text { (NIPPC) }\end{array}$ & 2 & 2007 & Em preenchimento \\
\hline & $\begin{array}{l}\text { Núcleo de Pesquisa sobre } \\
\text { Formação e Profissionalização } \\
\text { em Pedagogia (NUPPED) }\end{array}$ & 2 & 2004 & Certificado \\
\hline & $\begin{array}{l}\text { Núcleo de Formação de } \\
\text { Professores (FORMAÇÃO) }\end{array}$ & 1 & 2004 & Certificado \\
\hline & $\begin{array}{l}\text { Grupo de Estudos e Pesquisa em } \\
\text { Ensino e Formação de } \\
\text { Professores de Ciências } \\
\text { (GRUPEC) }\end{array}$ & 1 & 2002 & Certificado \\
\hline $\begin{array}{l}\text { UFMA Conceito } \\
4\end{array}$ & $\begin{array}{l}\text { Escola, Currículo e Formação } \\
\text { Docente (nome no site do } \\
\text { programa) } \\
\text { Escola, Currículo, Formação e } \\
\text { Trabalho Docente (nome no } \\
\text { diretório) }\end{array}$ & 1 & 2003 & $\begin{array}{l}\text { Certificado } \\
\text { Não-atualizado há } \\
\text { mais de } 12 \text { meses }\end{array}$ \\
\hline $\begin{array}{l}\text { FUFSE Conceito } \\
4\end{array}$ & $\begin{array}{l}\text { Formação e Atuação de } \\
\text { Educadores (INTERAÇÃO) }\end{array}$ & 1 & 2012 & Certificado \\
\hline \multirow[t]{2}{*}{$\begin{array}{l}\text { UFAL } \\
\text { Conceito } 3\end{array}$} & $\begin{array}{l}\text { Formação de Professores e } \\
\text { Ensino de Ciências }\end{array}$ & 2 & 2004 & Certificado \\
\hline & $\begin{array}{l}\text { Ensino, Pesquisa, Extensão e } \\
\text { Formação Docente }\end{array}$ & 4 & 2012 & Certificado \\
\hline $\begin{array}{l}\text { UFRPE } \\
\text { Conceito } 3\end{array}$ & $\begin{array}{l}\text { Grupo de Estudos em Educação } \\
\text { Ambiental, Docência e Questões } \\
\text { Contemporâneas. }\end{array}$ & 3 & 2010 & Certificado \\
\hline
\end{tabular}

Fonte: Elaboração das autoras com base em dados do DGP/CNPq, consultado em 10/2018.

O Quadro 4 revela que metade dos grupos de pesquisa em que o nome de todas as linhas aborda explicitamente a formação possui apenas uma linha de pesquisa. Nos demais 
grupos de pesquisa, cinco focalizam o tema em duas linhas, dois em três linhas e apenas em um grupo a referência aparece em 4 linhas que o compõe, conforme exemplifica a transcrição:

NOME DO GRUPO DE PESQUISA:

Ensino, Pesquisa, Extensão e Formação Docente

LINHAS DE PESQUISA:

- Abordagens teórico-metodológicas em Geografia e a formação docente

- Identidade e Formação Docente

- Identidade e Profissionalização Docentes

- Letramento e Formação Docente

- Políticas de Formação Docente e Trabalho Pedagógico.

(Extraído do DGP do CNPq em 09/2018).

Essa sub-amostra dos grupos de pesquisa que investigam a formação de professores evidencia uma expressiva variação no ano de criação dessas equipes. O período de criação dos 87 grupos de pesquisa que investigam a formação de professores reflete a significativa expansão da pesquisa nessa área nas três últimas décadas, visto que nos anos de 1990 e ao longo das duas primeiras décadas do século XXI cresce, de modo acelerado, a discussão sobre a Política Nacional de Formação de Profissionais do Magistério em todo o país (ANDRÉ, 2009).

Prevalecem lideranças femininas (52) nos 87 grupos de pesquisa que investigam a formação de professores, registrando-se certo equilíbrio nesse exercício entre lideranças masculinas (16) e mistas (um homem e uma mulher) (19). Este cenário traz à tona conquistas de espaços historicamente negados à mulher e corrobora com uma recente pesquisa publicada pela Elsevier, em março de 2017, sobre a questão de gênero na produção científica: O Brasil é líder em igualdade de gênero entre cientistas. Um dado animador para o nosso país revelado nessa pesquisa é que nos últimos anos as mulheres superaram a disparidade histórica e já produzem $49 \%$ de todos os trabalhos publicados no país. (GALILEU, 2017).

No que concerne a situação de cadastro dessas equipes junto ao Diretório do CNPq, os dados dos 87 grupos de pesquisa que declaram explicitamente que investigam a formação de professores inquietam, pois foram identificados 5 excluídos, 12 sem atualização há mais de um ano e 14 em preenchimento, movimento que reflete a falta de cuidado com o preenchimento desses dados e recai sobre a invisibilização de pesquisas e pesquisadores o que pode vir a fragilizar a atuação do próprio trabalho de formação e pesquisa que esses programas desenvolvem.

A caracterização apresentada evidencia quem são os 87 grupos de pesquisa que investigam a formação de professores nos 15 programas de pós-graduação em Educação do 
Nordeste que compõem a amostra desta investigação, instigando questionamentos sobre $o$ que e como produzem conhecimento sobre o tema.

\section{Grupos de Pesquisa que investigam a Formação de Professores no Nordeste: o que e como se produz}

Entende-se que a expressão "o que se produz" alude ao conteúdo da produção do conhecimento sobre a formação de professores nos grupos de pesquisa, ou seja, o assunto ou aspecto investigado, as preocupações que movem os estudos, seus objetivos e aporte teórico e/ou autores de referências. A expressão "como se produz", por sua vez, faz referência a elementos de ordem metodológica, tais como a abordagem privilegiada, o tipo de pesquisa adotado, os procedimentos de coleta e de análise de dados.

Com esteio nesse entendimento buscou-se captar essas informações por meio da Plataforma Lattes, tanto no Diretório de Grupos de Pesquisa quanto no Currículo Lattes de suas lideranças, considerando aspectos relacionados as pesquisas realizadas e em andamento (temas, objetivos, problema, aporte teórico e/ou autores de referências, metodologia, financiamento e orientações), bem como parcerias e articulações (convênios, participação em redes, articulações interinstitucionais, parceiros nacionais e internacionais etc.).

As análises encontram-se condensadas nos três subtópicos que seguem, abordadas a partir dos estratos avaliativos dos programas de pós-graduação em Educação a que os grupos encontram-se vinculados.

\subsection{Grupos de Pesquisa vinculados a Programas com conceito 5}

Os grupos de pesquisa que investigam a formação de professores vinculados a pósgraduação stricto sensu do Nordeste com conceito 5 são as equipes mais antigas da amostra desta investigação, apresentando pesquisadores com trajetória construída sobretudo nos anos 2000. A formação de professores aparece delineada progressivamente como objeto de estudo nos percursos de suas lideranças, as quais possuem formação em áreas situadas no âmbito das Ciências Humanas.

As pesquisas coordenadas pelas lideranças evidenciam a constituição paulatina de ênfases temáticas nos investimentos acadêmicos feitos por esses pesquisadores, nos quais está manifesto a preocupação com a formação do pedagogo, a formação inicial de licenciados, o 
estágio e a formação pedagógica na docência universitária, as tecnologias de informação e comunicação na formação de professores, a docência universitária na área da Saúde, os riscos do atrelamento da formação e da prática docente aos interesses do mercado, além da inovação pedagógica no currículo de formação, a relação ensino, pesquisa e desenvolvimento docente.

As pesquisas, a maioria empíricas, declaram adotar uma abordagem qualitativa, transitam entre delineamentos históricos e contemporâneos, e recorrem a estratégias diversificadas de produção de dados, desde questionários, (impresso ou eletrônico), observação de documentos, entrevistas semiestruturadas. No preenchimento das informações sobre o projeto de pesquisa prevalece a descrição dos objetivos, poucos dados sobre o problema e informações gerais acerca do referencial teórico e metodologia adotada. Varia bastante o registro de uso de softwares nos estudos desenvolvidos, de colaboração de estrangeiros e de participação em rede de pesquisa.

Verificou-se, ainda, que são as lideranças dos 35 grupos de pesquisa vinculados a pós-graduação stricto sensu com conceito 5 aquelas que contaram com mais financiamento para suas pesquisas. Também é nesse segmento que se verificou menor incidência de equipes com status "em preenchimento" e "excluído" (apenas 1 em cada).

\subsection{Grupos de Pesquisa vinculados a Programas com conceito 4}

Do total de 32 grupos de pesquisa do Nordeste que compõe a amostra deste estudo por declarar investigar a formação de professores, considerando o estrato avaliativo 4, um é vinculado ao Programa de Pós-Graduação em Educação da Universidade Federal do Maranhão, 3 grupos são vinculados ao Programa Mestrado Profissional em Educação de Jovens e Adultos da Universidade do Estado da Bahia, 4 vinculados ao Programa de PósGraduação em Educação Profissional vinculado ao Instituto Federal de Educação, Ciência e Tecnologia do Rio Grande do Norte, 8 estão vinculados ao Programa de Pós-Graduação em Educação da Universidade Federal da Paraíba e 16 estão vinculados ao Programa de PósGraduação em Educação da Universidade Federal do Sergipe, totalizando juntos 34 linhas de pesquisa. Desse conjunto de grupos de pesquisa, um total de 5 aparece notificada com o status de "grupo excluído", 3 com status de "grupo em preenchimento" e 1 de "grupo não atualizado há mais de 12 meses".

As investigações abordam a formação de professores a partir de estudos sobre autobiografia, formação de educadores sócio-comunitários, Teoria das Representações 
Sociais, à docência em contexto de formação inicial no âmbito do PIBID, a relação trabalho e educação e a interface com a formação de professores, o ensino de matemática, o estágio curricular na pedagogia, a valorização da docência pela via da formação continuada, a formação de professores na perspectiva da educação inclusiva, saberes docentes, a subjetividade docente e as histórias de vida.

As análises evidenciaram 3 pesquisas com participação em rede e 2 pesquisas com parcerias com outras universidades, mas há ausência de colaboradores estrangeiros, de participação em redes de pesquisa e de uso de software nas atividades de pesquisa, conforme os registros existentes no DGP/CNPq no período da consulta. A descrição e o preenchimento da plataforma é bastante sucinta no que diz respeito ao referencial teórico e métodos adotados, detendo-se na apresentação dos objetivos e com escassa ou nenhuma informações sobre o problema das pesquisas.

Destacam-se investigações com abordagem qualitativa, empírica e do tipo estudo de caso, pesquisa-formação e iniciativas do tipo estado da arte, com recorrência a procedimentos como entrevista semiestruturada, observação participante, diário de classe, fotografias e material midiático. Pesquisas com financiamento aparecem entre algumas lideranças, verificando-se, contudo, maior regularidade desse apoio entre pesquisadores com percurso mais consolidados na pesquisa.

\subsection{Grupos de Pesquisa vinculados a Programas com conceito 3}

Do total de 20 grupos de pesquisa do Nordeste que compõe a amostra deste estudo por declarar investigar a formação de professores, considerando o estrato avaliativo 3, identificou-se 10 grupos vinculados ao Programa de Pós Graduação em Educação da Universidade Federal de Alagoas, 5 grupos vinculados ao Programa de Pós Graduação da Universidade Federal de Campina Grande, 2 grupos vinculados ao Programa de PósGraduação da Universidade Federal Rural de Pernambuco, 2 vinculados ao Programa de PósGraduação em Gestão de Ensino da Educação Básica da Universidade Federal do Maranhão, e 1 está vinculado ao Mestrado Profissional em Educação da Universidade Regional do Cariri, totalizando juntos 37 linhas de pesquisa. Dois desses grupos de pesquisa, no período da consulta ao DGP do CNpq, foram identificados com o status "em preenchimento".

Os grupos registram estudos no campo da formação de professores olhando para contextos formais e não formais de educação, destacando os saberes, a identidade e as práticas 
docentes a partir do pensamento freiriano, estudos sobre currículo, construção de saberes científicos, a formação docente para a educação de surdos, políticas públicas para a educação e a análise das condições de trabalho, formação, atuação e avaliação, no entanto, poucas pesquisas feitas pelas lideranças desses grupos informam ter recebido financiamento. Os grupos informaram ter parcerias com outras universidades ou pesquisadores estrangeiros.

No geral, são pesquisas com abordagem qualitativa, que envolvem observação participante, entrevista semiestruturada e o exame de documentos como técnicas de produção de dados. Na descrição da maioria dessas iniciativas, entretanto, não foi identificado o problema norteador das investigações nem o aporte teórico em que se fundamentam. Constatou-se que estes exploram o tema correlacionado a discussões sobre interdisciplinaridade, teorizações culturais e sociais contemporâneas sobre estratégias de aprender e ensinar, sobretudo na formação continuada dos professores.

O inventário apresentado revela grupos de pesquisa robustos, interesses com foco temático diversificado e lideranças formadas por adultos jovens com alta qualificação, os quais demonstram forte capacidade de captação de financiamento de suas pesquisas. Aliás, um aspecto em comum entre as 87 equipes focalizadas nessa análise refere-se ao indicativo do $\mathrm{CNPq}$ como a principal agência de fomento da pesquisa na área da Educação, seguido das Fundações de Apoio a Pesquisa (FAPS) dos Estados e da CAPES. Por outro lado, verificou-se o silenciamento de informações acerca da participação em rede de pesquisa, de pesquisadores colaboradores estrangeiros e de parcerias internacionais. Será este silêncio apenas reflexo do preenchimento incompleto dos dados dessa equipe no Diretório dos Grupos Pesquisa do CNPq? Esta é uma questão que se sobressai, preocupa e merece atenção por parte dos programas de pós-graduação em face do movimento de internacionalização e de suas implicações sobre avaliações futuras.

\section{Contribuições para o campo de estudo da Formação de Professores}

Que sinalizações podem ser extraídas desse estudo inventariante sobre grupos de pesquisa que investigam a formação de professores, precisamente de equipes vinculadas a pós-graduação stricto sensu em Educação do Nordeste?

A princípio, cabe destacar que a atenção sobre o processo associativo de pesquisadores em torno de grupos de pesquisa nas mais diversas áreas, em particular na Educação, é revelador do potencial dessa estratégia para o desenvolvimento do conhecimento 
científico e, principalmente, para a constituição e consolidação de campos específicos (MOREIRA; VILAN FILHO; MUELER, 2015; FARIAS; RAMOS; PIMENTEL, 2018). É justamente o reconhecimento desse potencial que tem mobilizado ações como o Simpósio de Grupos de Pesquisa sobre Formação Docente, realizado pelo GT 8 (Formação de Professores) da Associação Nacional de Pós-Graduação e Pesquisa em Educação (ANPED) com o objetivo de "promover a discussão sobre a delimitação do campo de formação de professores com base no mapeamento dos grupos de pesquisa que focalizam essa temática no Brasil" (ROLDÃO et all., 2018). As análises desse escrito, de certo modo, somam-se a esse desiderato, uma vez que o boom da formação de professores como tema de pesquisa em Educação também trouxe inquietações "acerca de sua especificidade e das questões teórico-metodológicas que a caracterizam" (SILVA; NÓBREGA-THERRIEN; FARIAS, 2014, 129).

Com efeito, o estudo ora apresentado, evidenciou o significativo interesse pela formação de professores entre os grupos de pesquisa do Nordeste (cerca de um terço das equipes que compuseram a amostra), confirmando indicativos de estudos nacionais relativos que registram o crescimento da produção na área (JARDILINO, 2011; ANDRÉ; BRZEZINSKI; LÜDKE; ROLDÃO, 2010, entre outros). Movimento, aliás, que reforçou a ampliação dos focos de análise, o que também se verificou no âmbito das frentes de estudos dos grupos de pesquisa do Nordeste, marcadas pela abordagem de aspectos variados acerca do tema, diferentes níveis e modalidades de ensino, além de diversos contextos e interfaces com áreas específicas de conhecimento. Frentes de estudos que contemplam desde a formação inicial e continuada e em serviço para a docência na Educação Básica e universitária, a formação do pedagogo, a formação em áreas específicas de conhecimento, bem como abordando a interface formação e currículo, formação e tecnologias, formação e profissionalização, formação e aprendizagem, formação e representação, formação e alfabetização/letramento, formação e interdisciplinaridade, formação e gestão, formação e avaliação, formação e saúde, formação e ética, formação e educação ambiental. Enfim, há uma nítida heterogeneidade nos focos de estudos sobre a formação de professores nos grupos de pesquisa do Nordeste, tornando mais que pertinente o alerta sobre a necessária vigilância epistemológica em torno do foco e da identidade desse campo investigativo.

Considerando ainda o último relatório do Simpósio de Grupos de Pesquisa sobre Formação de Professores realizado pelo GT8 da ANPED (ROLDÃO et all., 2018), identificou-se algumas tendências nos registros sobre o que produzem e como produzem grupos de pesquisa do Nordeste que investigam a formação de professores, comentadas a 
seguir a partir do aspecto evidenciado no exame dos dados dessas equipes na Plataforma Lattes:

a) Pesquisas que abordam a formação de professores mirando na escola pública e nos

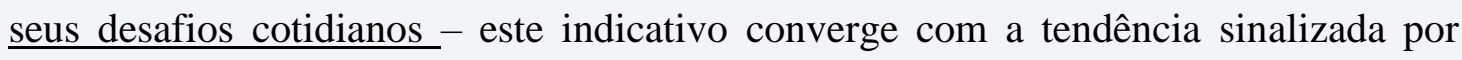
Roldão et all. (2018, p. 14) de pesquisas que buscam "maior articulação universidadeescolas públicas", verificando-se clara preocupação por parte dos líderes dos grupos em desenvolverem "investigações buscando um diálogo da pesquisa com as escolas públicas de Educação Básica”.

b) Focalização das linhas de pesquisa e de temáticas associadas a prática pedagógica tendência denominada pelas autoras supracitadas de "ênfase na prática e nos significados atribuídos a ela" (ibidem). Embora esta tendência possa indicar a emergência de objetos de estudo mais próximos a questões que atravessam a formação docente, ela carreia preocupações pela possibilidade de "resvalar em praticismo", sendo importante não perder de vista que a prática pedagógica precisa ser problematizada, evidenciando-se por que se estuda essa prática e o que se busca explicitar quanto à formação de professores a partir dessa prática.

c) Indicação de pesquisa com abordagem qualitativa e prevalência de estudos empíricos - esses aspectos são predominantes na descrição dos estudos arrolados pelos grupos de pesquisa do Nordeste, os quais, em geral, também são estudos micros, via de regra identificados como estudos de caso. Não se verificou o desenvolvimento de pesquisas em grande escala ou mesmo de estudos longitudinais. Esses indicativos alinham-se às tendências de "alguma perda de rigor metodológico" em face do silenciamento da fundamentação adotada, bem como de "escassez de estudos extensivos, de maior escala, com quantificação de tendências" apontadas por Roldão et all. (2018).

d) Reduzida visibilidade de parcerias internacionais - indicativo que diverge da tendência de "reforço de parcerias internacionais" sinalizada no relatório do III Simpósio de Grupos de Pesquisa sobre Formação de Professores. No Nordeste, considerando o registro dos grupos de pesquisa na Plataforma Lattes, o que se verificou na amostra desse estudo foi o silenciamento dos processos associativos mais amplos, na perspectiva "de dentro para fora" (interinstitucional, participação em rede de pesquisa, cooperações internacionais etc). Sobre essa tendência, não é demais advertir que o preenchimento incompleto das informações inseridas no Diretório dos Grupos de Pesquisa do $\mathrm{CNPq}$ tende a fornecer um retrato desconfigurado das 
pesquisas desenvolvidas e em desenvolvimento por essas equipes e, sobretudo, de seu papel, relevância e contribuição para o avanço da produção de conhecimento na área.

e) Tímido incremento no financiamento de pesquisas por parte das agências externas de fomento é outra tendência que se sobressai nas iniciativas anotadas pelos grupos de pesquisa do Nordeste e que dialoga com as análises de Roldão et all. (2018, p. 17) ao sublinhar: “[...] constatamos uma perspectiva animadora, já que muitos dos grupos apresentados tinham financiamento de órgãos de fomento".

As tendências explicitadas revelam permanências que desafiam o desenvolvimento e a consolidação do campo da formação de professores, ao tempo em que mostram sua potência e importância para fortalecer a área da Educação como campo científico junto à sociedade em geral, particularmente às agências de estímulo ao desenvolvimento da pesquisa.

\section{REFERÊNCIAS}

ANDRÉ, M. E. D. A. A produção acadêmica sobre formação docente: um estudo comparativo das dissertações e teses dos anos 1990 e 2000. Revista Brasileira de Pesquisa sobre Formação de Professores, v. 1, n. 1, p. 41-56, ago./dez. 2009.

ANDRÉ, M; BRZEZINSKI, I; LÜDKE, M; ROLDÃO, M do C. Pesquisa sobre formação de professores: síntese do II Simpósio de grupos de pesquisa do GT 8 da ANPED. Revista Formação Docente, Belo Horizonte, v. 022, nº 03, p.152-159, ago./dez. 2010.

ANDRÉ, M. E. D. A.; ROMANOWSKI, J. P. Estado da arte sobre formação de professores nas dissertações e teses dos programas de pós-graduação das universidades brasileiras, 1990 a 1996. In: REUNIÃO ANUAL DA ASSOCIAÇÃO NACIONAL DE PÓS-GRADUAÇÃO E PESQUISA EM EDUCAÇÃO - ANPED, 22, 1999, Caxambu-MG, Programa e Resumos.

BRASIL. MEC. CAPES. Plano Nacional de Pós-Graduação - PNPG 2011-2010. Brasília: DF: CAPES, 2010.

CAVAlCANTE, M. M. D; NUNES, J. B. C.; FARIAS, I. M. S. de (Orgs.). Pesquisa em Educação na UECE: um caminho em construção. Fortaleza: Edições Demócrito Rocha, 2002.

FARIAS, I. M. S. de; JARDILINO, J. R. L.; SILVESTRE, M. A.; ARAÚJO, R. M. B. de. Pesquisa em Rede: diálogos de formação em contextos coletivos de conhecimento. Fortaleza: EdUECE, 2018.

FARIAS, I. M. S. de; RAMOS, J. F. Pouchain; PIMENTEL, S.. Apontamentos sobre a formação de professores nos estudos e produções do grupo de pesquisa EDUCAS/UECE: percursos e perspectivas. Formação Docente, Belo Horizonte, v. 10, n. 19, p. 13-32, jul./dez. 2018. 
FERREIRA, N. S. de A.. As pesquisas denominadas “estado da arte”. Revistas Educação \& Sociedade, $\mathrm{n}^{\circ} 79$, p. 257-272, ago./2002.

FURTADO, B. A.. Pesquisa em rede: análise preliminar dos grupos de pesquisa do CNPq em 2014. Radar, $n^{\circ}$ 45, junho de 2016. Disponível em:

<Repositorio.ipea.gov.br/bitstream/11058/6879/1/Radar_n45_pesquisa.pdf >. Acessado em: 28 dez. 2017.

GALILEU. O que você precisa saber sobre a pós-graduação no Brasil. In: Revista Galileu, notícia de 09/08/2017: Disponível em:

$<$ https://revistagalileu.globo.com/Revista/noticia/2017/08/o-que-voce-precisa-saber-sobrepos-graduacao-no-brasil.html> Acesso em 18 out. 2018.

HOUAISS, A.; VILLAR, M. de S.. Dicionário Houaiss da língua portuguesa. Instituto Antônio Houaiss de Lexicografia e Banco de Dados da Língua Portuguesa S/C Ltda. $1^{\text {a }}$ Ed. Rio de Janeiro: Objetiva, 2009.

MACHADO, N. J. A Universidade e a organização do conhecimento: a rede, o tácito, a dádiva. Estudos Avançados, vol.15 no.42, São Paulo May/Aug. 2001. Disponível em: http://www.scielo.br/scielo.php?script=sci_arttext\&pid=S0103-40142001000200018. Acessado em: 31/12/17.

MATOS, K. S. L. de; VIEIRA, S. L.. Pesquisa Educacional: o prazer de conhecer. Fortaleza: Edições Demócrito Rocha; UECE, 2001.

MOREIRA, J. R.; VILAN FILHO, J. L.; MUELLER, Suzana Pinheiro Machado. Características e produção científica dos grupos de pesquisa do CNPq/DGP nas áreas de Ciência da Informação e Museologia (1992 - 2012). Perspectivas em Ciência da Informação, v. 20, n.4, p.93-106, out./dez. 2015.

ROLDÃO. M. do C.; ANDRÉ, M; BRZEZINSKI, I; ROMANOWSKI, J. P.; LIMA, E. F. III Simpósio de Grupos de Pesquisa sobre Formação de Professores do Brasil - Síntese das observações realizadas. Revista Formação Docente, Belo Horizonte, v. 10, nº 18, p.11-18, jan./jul. 2018.

SILVA, S. P.; NÓBREGA-THERRIEN, S. M.; FARIAS, I. M. S. de. Produções sobre a formação de professores no EPENN: análise do período 2003 a 2011. In: GOMES, A. M.; LEAL, T. F. Pesquisas em Educação nas regiões Norte e Nordeste: balanço e perspectivas. Recife: editora UFPE, 2014, p.127-152.

\section{SOBRE AS AUTORAS:}

\section{Isabel Maria Sabino de Farias}

Doutorado em Educação Brasileira (UFC). Professora Associada do Centro de Educação e do Programa de Pós-Graduação em Educação da Universidade Estadual do Ceará (UECE). Líder do Grupo de Pesquisa Educação, Cultura Escolar e Sociedade (EDUCAS)

E-mail: Isabel.sabino@uece.br

(iD https://orcid.org/0000-0003-1799-0963 


\section{Marília Duarte Guimarães}

Doutoranda em Educação Brasileira (UFC) Professora do Instituto Federal de Educação, Ciência e Tecnologia do Ceará (IFCE). Programa de Pós-Graduação em Educação Brasileira (PPGEB) Integrante do Grupo de Pesquisa em Formação Docente, História e Política Educacional. E-mail: mariliaguimaraes.trab@hotmail.com

(iD https://orcid.org/0000-0001-6808-1570

\section{Ingrid Louback de Castro Moura}

Doutorado em Educação (UFC). Professora Adjunto II da Universidade Federal do Ceará. E-mail: ingrid.louback@gmail.com

(iD) https://orcid.org/0000-0003-2395-6147 